\title{
INFLUENCE OF HYPERCALCEMIA AND ELEVATED PARATHYROID HORMONE LEVEL IN THE DEVELOPMENT OF TYPE 2 DIABETES
}

Brutskaya - Stempkovskaya E. V. ${ }^{1,2}$,Shepelkevich A.P1

Belarusian State Medical University ", Minsk city polyclinic N312, Belarus

Introduction: Status of carbohydrate metabolism in patients with primary hyperparathyroidism (PGPT) has been studied extensively in recent years, but the results of studies on the impact of long-term elevated levels of parathyroid hormone and hypercalcemia on the risk of type 2 diabetes continues to be in the discussion.

Objective: to examine the prevalence of type 2 diabetes in patients with manifested and asymptomatic PGPT.

\section{RESULTS:}

\section{PREVAlence Of TYPe 2 diabetes}

\section{MATERIALS \\ AND \\ METHODS:}

136 patients with PGPT:

- asymptomatic PGPT:

mean age was

$51.5 \pm 11.6$ years

- manifested PGPT:

mean age was $52 \pm 10.4$ years

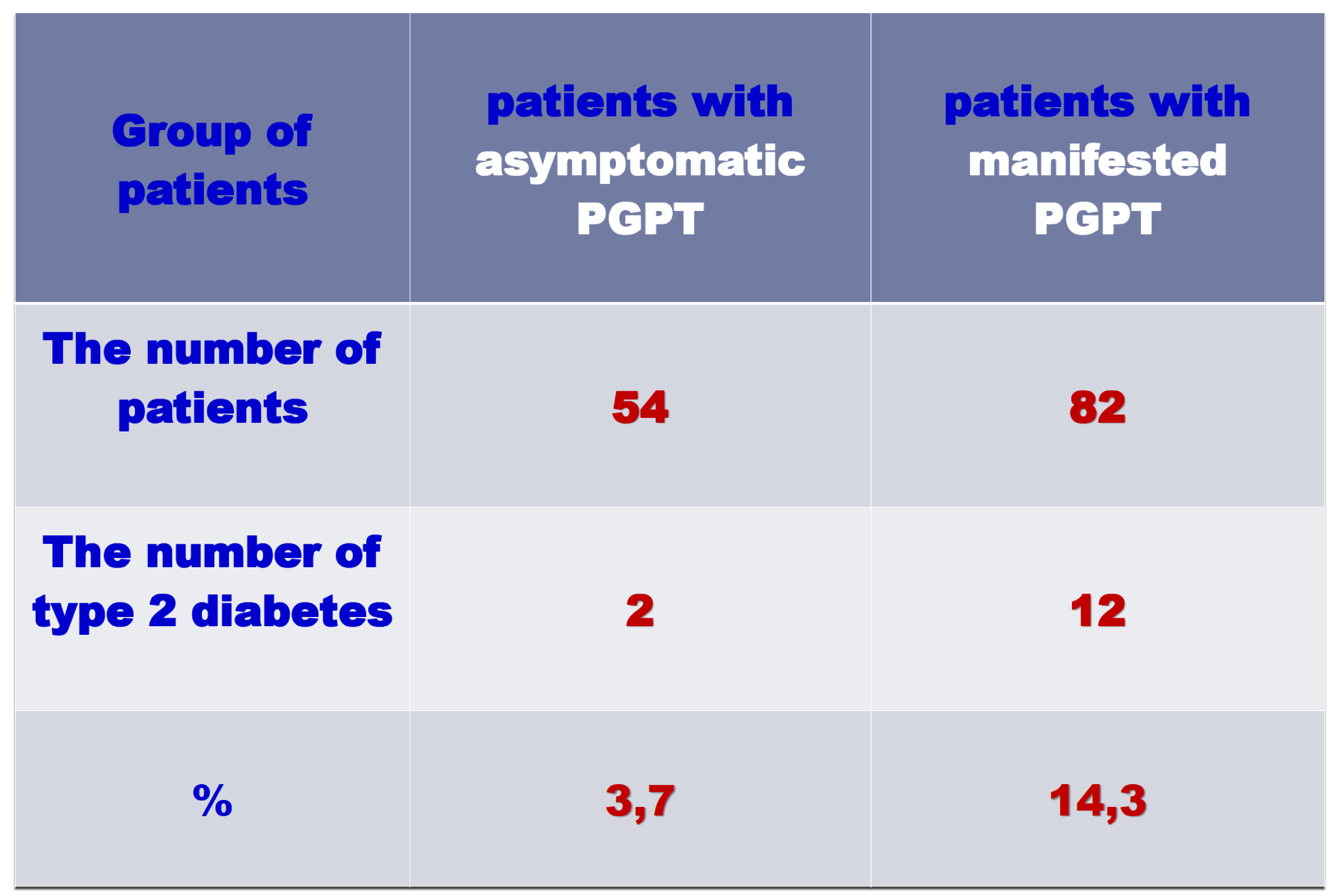

Significant differences was detected in the prevalence of type 2 diabetes in both groups of patients with PGPT $(p<0,05)$.

\section{CONCLUSION:}

The results of the study have shown an increasing prevalence of type 2 diabetes in patients with manifested PGPT compared with asymptomatic PGPT. The results may indicate the influence of long-term hypercalcemia and elevated levels of parathyroid hormone in the frequency of manifestation of type 2 diabetes in patients with PGPT. 